\title{
Use of endotracheal tubes in continuous aspiration of subglottic secretions: Knowledge and expertise of respiratory therapists and nurses
}

\author{
Abdullah Alanazi, Mohammed Al-Saba'ani, Rami Al Khalid, Abdulaleem Alatassi, Al-oraibi Saleh, \\ Shoeb Qureshi \\ College of Applied Medical Sciences, King Saud Bin Abdul-Aziz University for Health Sciences, Riyadh, Saudi Arabia. \\ Correspondence: Shoeb Qureshi. Address: College of Applied Medical Sciences, King Saud Bin Abdul-Aziz University for \\ Health Sciences, P.O. Box 3660, Riyadh-11481, Saudi Arabia. Email: qsab2002@yahoo.co.in
}

Received: October 30, 2013

Accepted: March 20, $2014 \quad$ Online Published: April 23, 2014

DOI : $10.5430 /$ jnep.v4n7p49

URL: http://dx.doi.org/10.5430/jnep.v4n7p49

\begin{abstract}
Introduction: Ventilator-associated pneumonia (VAP) is a hospital acquired nosocomial infection that is commonly found in patients receiving mechanical ventilation. Continuous aspiration of subglottic secretions (CASS) is found to lower the incidence of VAP. The aim of this study was to assess respiratory therapists and nurses' awareness and experiences about the Endotracheal Tubes (ETT) with CASS.

Methodology: This is a cross-sectional study. Purposive sampling of 51 respiratory therapists and 51 nurses who were involved in taking care of critically ill patients in adult ICUs at King Abdul-Aziz Medical City, Riyadh were used. The questionnaire was related to the knowledge and experiences of respiratory therapists and nurses about the proper use of ETT with CASS.

Results: The results suggest that the respiratory therapists were more knowledgeable in the use of ETT-CASS. However, both respiratory therapists and nurses had problems related to ETT design and materials. Most of these problems were related to cuff materials and its design, suctioning system and tubes, in addition to the availability of the equipment.

Conclusion: This study presents a unique contribution to knowledge about the experiences of respiratory therapists and nurses who work in KAMC about the proper use of ETT-CASS. The results of this study showed that the use of ETT-CASS is yet to be popularly recognized. Thus, it should be acclaimed by further studies and promotion through formulation of updated protocols and educational programs.
\end{abstract}

\section{Key words}

Ventilator-associated pneumonia, Respiratory therapists, Nurses, Endotracheal Tubes

\section{I ntroduction}

Emergency intubation is a requisite that is immensely expended as a life-saving procedure in severe acute illness and injury associated with potential compromises to the patient's airway and ventilation. Aggressive treatment maneuvers such as endotrachial intubation and mechanical ventilation are often practiced in the pre-hospital/emergency department (ED) phase of care ${ }^{[1]}$. Care by mechanical ventilation is apt to cause ventilator-associated pneumonia (VAP) which is a hospital 
acquired nosocomial infection. Continuous aspiration of subglottic secretions is found to lower the incidence of VAP ${ }^{[2,3]}$. The incubation period required for VAP is 48 hour or more ${ }^{[4]}$. Among all the intensive care unit (ICU)-acquired infections, the incidence of VAP is $27 \%-47 \%$ and it is the second most common nosocomial infections in the United States ${ }^{[5]}$. The pathogenesis of VAP is supposed to result from the seepage of contaminated secretions from oropharynx around the endotracheal tube cuff and into the lung. The nosocomial pneumonia is hypothesized to result from colonization of bacteria in the oropharynx, which causes pulmonary infection ${ }^{[6-9]}$.

Although cuffed ETT is used in management of airway and protection against a huge volume of aspiration, they do not assure prevention of VAP, which is most often caused by aspiration of small volumes around the cuff. The ETT can also cause mucosal injuries and reduce mucociliary function, in addition to worsening upper airway defenses ${ }^{[10]}$. Furthermore, the ETT create binding sites for bacteria in the bronchial tree and increases mucus secretion and accumulation of secretions, thereby promoting the adherence of bacteria. Thus ETT increases the entry of bacteria into the lung, which serves as an inaccessible reservoir to host defenses ${ }^{[1]}$.

The movement of secretions from the oral cavity into the subglottic space and into lung increase the risk of VAP, hence; an effective ETT cuff seal may reduce movement of the exudation. The suggested range for ETT cuff pressure is 20-30 cm $\mathrm{H}_{2} \mathrm{O}{ }^{[11]}$. Pressure below $20 \mathrm{~cm} \mathrm{H}_{2} \mathrm{O}$ is a greater indication of pneumonia risk ${ }^{[12]}$. Higher ETT cuff pressure is also associated with tracheal mucosal damage ${ }^{[13]}$. Hence, a special ETT with an additional length covering the lumen and a port to allow CASS has been designed ${ }^{[4]}$.

Thus the system ETT-CASS requires a thorough awareness and training of the health care professionals, specially the respiratory therapists and nurses, who are involved in the critical care of tracheal intubation and mechanical ventilation. The purpose of the present study is to analyze the knowledge and ability of the respiratory therapists and nurses in performance of the procedure of ETT with CASS.

\section{Methodology}

\subsection{Aim of the study}

The aim of this study was to assess respiratory therapists and nurses' awareness and experiences about the Endotracheal Tubes (ETT) with Continuous Aspiration of Subglottic Secretions (CASS).

\subsection{Study design and setting}

A cross-sectional design study was conducted to analyze the knowledge and expertise of the respiratory therapists and nurses who are involved in taking care of critically ill patients in adult ICUs at King Abdullah Medical City (KAMC), Riyadh.

\subsection{Sample size}

Purposive sampling included 51 respiratory therapists and 52 nurses who were involved in taking care of critically ill patients in adult ICUs.

\subsection{I nclusion \& exclusion criteria}

Qualified Respiratory Therapists and nurses in the employment of KAMC were the criteria of Inclusion. The nonqualified RT, nurses and professionals including interns, students, and trainees other than RT and nurses course constituted the Exclusion criteria.

\subsection{Sampling method, data collection and statistics}

The method is by questionnaire served to the RT and nurses enrolled for the study. The purpose of study was explained before issuing the questionnaires. The questionnaire included 11 questions about the awareness and knowledge related to 
ETT - CASS. The questionnaire was created to include questions related to the proper use of ETT - CASS and the knowledge and awareness of Respiratory therapists and nurses. The questionnaire was authenticated using consensual rationality by consulting about twenty experts at the score domain area of respiratory care and application of these specialized endotracheal tubes. Anesthesiologists and Respiratory Therapists were consulted and changes to some questionnaires were made.

\subsection{Data analysis and statistics}

One hundred and ten questionnaires were distributed at KAMC, Riyadh on April 2012 and 104 questionnaires were collected on the same day of distribution giving a response rate of $95 \%$. After completion of the data collection process, questionnaire responses were reviewed, organized, tabulated and statistically analyzed using Statistical Package for Social Sciences (SPSS, version 16.0).

\subsection{Ethical considerations}

The study was approved by the Ethics Committee of KAMC, National Guards.

\subsection{Characteristics of the samples}

Respiratory Therapists: The Respiratory therapists were in the age group of 30-45 years. All of them were qualified. Majority of them were experienced more than 10 years as an RT.

Nurses: The nurses were in the age group of 25-40 years. All of them were qualified nurses. Majority were experienced more than 12 years as a qualified nurse.

\section{Result}

A comparison of gender, age, specialty and experience was found to be insignificant ( $p>.05)$. However, between the nationality comparison showed non Saudi group was more knowledgeable than the Saudi group $(p<.030)$. Most of the respiratory therapists (84.3\%) and nurses (74.5\%), reported knowing ETT-CASS with almost half of respiratory therapists who knows ETT-CASS (58.1\%) had proper professional know-how. Regarding the purpose behind using ETT-CASS, $93 \%$ of the respiratory therapists and $89.4 \%$ of the nurses knew the idea behind using it. Additionally, almost $72 \%$ of the respiratory therapists and $79 \%$ of the nurses apply continuous suctioning as recommended. After analyzing knowledge questions we observed that respiratory therapists were more knowledgeable than nurses (see Figure 1). Regarding the proper use of the ETT-CASS, both respiratory therapists and nurses reported that they had problems related to the design of endotracheal tube and materials with less problems faced by respiratory therapists (see Figure 2).These problems were related to cuff materials and its design, suctioning system and tubes. Also more than third of respiratory therapists and nurses faced problems related to equipment availability.

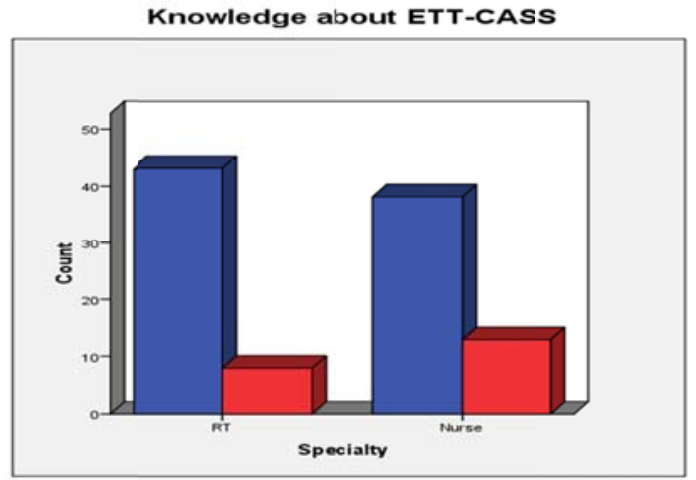

Figure 1. Health professional knowledge of ETT-CASS
The proper use of ETT-CASS

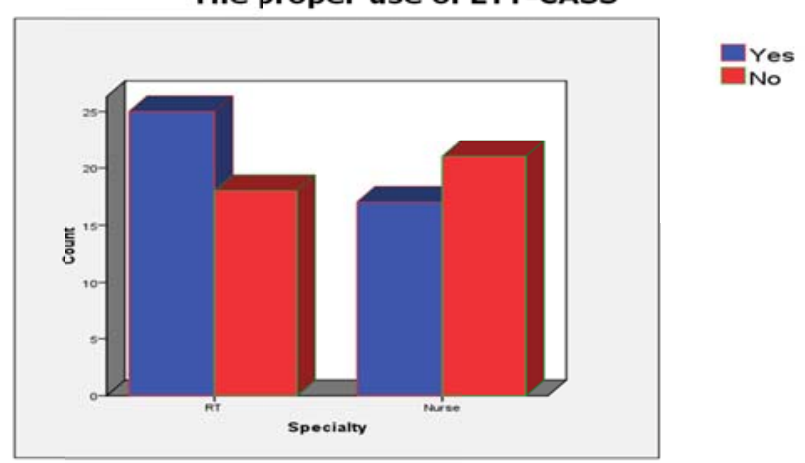

Figure 2. The proper use of ETT-CASS 


\section{Discussion}

Literature reports suggest considerable increase in the incidence of VAP which is linked with delayed removal of the tube, prolonged stays in the ICU and the hospital, increased morbidity and mortality and increased use of health care resources ${ }^{[14-17]}$. Hence, prevention of VAP is an essential objective of health care delivery in ICUs. In view of the signifycance of the problem, it was imperative to make surveys identifying the shortcomings and detection of the area that needs improvement. In our survey, we found that respiratory therapists were more knowledgeable than nurses, however; regarding the proper use of the ETT-CASS, both respiratory therapists and nurses reported that they had problems related to the design of ETT and materials with less problems faced by respiratory therapists. Most of these problems were related to cuff materials and its design, suctioning system and tubes, in addition to the availability of equipment. This study on use of ETT-CASS has explored some of the crucial points such as: (1) although, most of the respiratory therapists and nurses adhered to the recommended technique, there still existed some ambiguity on certain issues like the recommended suctioning pressure, (2) ambiguity about the alternative choices to evacuate the secretions when suction lumen is blocked and the associated complications, (3) adherence to and implementation of the adopted VAP prevention guidelines are variable and affected by lack of training and control program, lack of knowledge among health care providers ${ }^{[18]}$.

One of the studies has focused on identification of the knowledge of ICU nurses regarding measures to prevent VAP ${ }^{[18]}$. Other ICU health care providers - particularly respiratory therapists, who are involved in controlling endotracheal cuff pressure, avoiding micro-aspiration of subglottis secretions and controlling contamination of mechanical ventilator equipment can have a significant effect on the prevention of VAP in patients receiving mechanical ventilation in the ICU ${ }^{[19]}$. Nursing staff play a significant role in applying non-drug-based preventive measures directly related to the care they provide; nevertheless, adherence to recommendations varies widely ${ }^{[20]}$. Failure to comply has been ascribed to nurses' scientific knowledge ${ }^{[21]}$. Ricart et al. ${ }^{[22]}$, Observed that nurses had resistance to apply some preventive strategies. Many studies have analyzed nurses' theoretical knowledge regarding specific procedures, however; the application of this knowledge to practice has received little attention. ${ }^{[23]}$ Moreover, the instruments used in these studies (e.g., questionnaires) were mainly limited or not entirely appropriate ${ }^{[24]}$. Questionnaires may not be reliable measure of compliance as answers may not reflect performance. Thus, it is important to observe nursing practices in situ .method being adopted to reduce VAP incidence is the use of specialized ETT for CASS. The ETT-CASS is designed with a dorsal suction lumen above the cuff and the evacuation port is attached to suctioning machine for continuous evacuation of the secretions that accumulate above the cuff ${ }^{[25]}$. The ETT-CASS is found to be beneficial in reducing VAP incidence, thereby shortening the ventilator length, hospital stay, use of antimicrobial agents, and deterioration of pulmonary status. One of the clinical studies have shown that ETT-CASS reduces VAP incidence by almost half ${ }^{[26]}$. Notwithstanding the clinical benefits of ETT-CASS, there have been no reports on the clinical effects of its use either globally or in Saudi Arabia. There is a paucity of literature on the knowledge and awareness of ETT-CASS among respiratory therapists and nurses who are the main professionals to use the technique.

\section{Conclusion}

ETT-CASS system requires a thorough awareness and training of the health care professionals, (respiratory therapists and nurses), who are involved in the critical care of tracheal intubation and mechanical ventilation. The present study analyzed the knowledge and expertise of RTs and Nurses regarding ETT-CASS by a questionnaire. Respiratory therapists were more knowledgeable than nurses. Regarding the use of the ETT-CASS, both the professionals reported problems related to the design of endotracheal tube. These problems were related to cuff materials and its design, suctioning system and tubes. Also more than third of respiratory therapists and nurses faced problems related to equipment availability. The RT and nursing professionals may be exposed to additional training for the solution of problems they face in ETT-CASS and proper facilities may be provided. 


\section{References}

[1] Grap MJ, Munro CL, Unoki T, Hamilton VA, Ward KR. Ventilatior-associated Pneumonia - The potential critical role of emergency medicine in prevention. J Emerg Med. 2012; 42: 353-362. PMid:20692786 http://dx.doi.org/10.1016/j.jemermed.2010.05.042

[2] Shaw MJ. Ventilator-associated pneumonia. Curr Opin Pulmon Med. 2005; 11: 236-241. http://dx.doi.org/10.1097/01.mcp.0000159834.05401.78

[3] Wagh H., \&Acharya, D. Ventilator Associated Pneumonia Ventilator Associated Pneumonia-an Overview. British Journal of Medical Practitioners. 2009; 2(2): 16-19.

[4] Kollef MH. The prevention of ventilator-associated pneumonia.N. Engl J. Med. 1999; 340: 627-34. PMid:10029648 http://dx.doi.org/10.1056/NEJM199902253400807

[5] Shaikh MS, Devrajani BR, Ali Shah SZ, Akhund T, Bibi I. Frequency, pattern and etiology of Nosocomial infection in intensive care unit: An experience at tertiary care hospital. J. Ayub Med Coll, Abbottabad. 2008; 20: 37-40. PMid:19999200

[6] Papazian L, Bregeon F, Thirion X, Gregoire R, Saux P, Denis J P et al. Effect of ventilator-associated pneumonia on mortality and morbidity. .Am J respirat crit care med. 1996; 154: 91-97. PMid:8680705 http://dx.doi.org/10.1164/ajrccm.154.1.8680705

[7] Chastre J, and Fagon JY. Ventilator-associated pneumonia. Am J respirat and crit care med. 2002; 165: 867-903. PMid:11934711 http://dx.doi.org/10.1164/ajrccm.165.7.2105078

[8] Beachey, W., \& Wilkins, R. L. Respiratory care anatomy and physiology. Respiratory Care. 2008.

[9] Sole M, Penoyer D, Bennett A, Bertrand J, and Talbert S. Oropharyngeal Secretion Volume in Intubated Patients: The Importance of Oral Suctioning. Am J Crit Care. 2011; .20: e141-e145.

[10] Konrad F, Schreiber T, Brecht-Kraus D, Georfieff M. Mucociliary transport in ICU patients. Chest. 1994; 105: 237-41. PMid:8275739 http://dx.doi.org/10.1378/chest.105.1.237

[11] Diaz E, Rodriguez AH, Rello J. Ventilator-associated pneumonia: issues related to the artificial airway Respir Care. 2005; 50: 900-6. PMid:15972111

[12] Sole ML, Byers JF, Ludy JE, Ostrow CL. Suctioning techniques and airway management practices: pilot study and instrument evaluation. Am J Crit Care. 2002; 11: 363-8. PMid:12102437

[13] Galinski M, Treoux V, Garrigue B, Lapostolle F, Borron SW, Adnet F. Intracuff pressures of endotraceal tubes in the management of airway emergencies: the need for pressure monitoring. Ann Emerg Med. 2006; 47: 545-7. PMid:16713783 http://dx.doi.org/10.1016/j.annemergmed.2005.08.012

[14] Rello J, Ollendorf DA, Oster G, Vera-Llonch M, Bellm L, Redman R, et al. Epidemiology and outcomes of ventilator associated pneumonia in a large US database. Chest. 2002; 122: 2115-2121. PMid:12475855 http://dx.doi.org/10.1378/chest.122.6.2115

[15] Kollef MH. What is ventilator-associated pneumonia and why is it important? Respiratory care. 2005; 50: 714-724. PMid:15913464

[16] Safdar, N., Dezfulian, C., Collard, H. R., \& Saint, S. Clinical and economic consequences of ventilator-associated pneumonia: a systematic review. Crit care med. 2005; 33: 2184-2193. PMid:16215368 http://dx.doi.org/10.1097/01.CCM.0000181731.53912.D9

[17] Gupta, A., Agrawal, A., Mehrotra, S., Singh, A., Malik, S., \&Khanna, A. Incidence, risk stratification, antibiogram of pathogens isolated and clinical outcome of ventilator associated pneumonia. Indian Journal of Critical Care Medicine: Peer-reviewed, Official Publication of Indian Society of Crit Care Med. 2011; 15: 96. PMid:21814373 http://dx.doi.org/10.4103/0972-5229.83015

[18] Sierra R, Benitez E, Leon C, Rello J. Prevention and diagnosis of ventilator-associated pneumonia: a survey on current practices in Southern Spanish CCUs. Chest. 2005; 128: 1667-1673. PMid:16162773 http://dx.doi.org/10.1378/chest.128.3.1667

[19] Kaynar AM, Mathew JJ, Hudlin MM, Gingras DJ, Ritz RH, Jackson MR, et al. Attitudes of respiratory therapists and nurses about measures to prevent ventilator-associated pneumonia: a multicenter, cross-sectional survey study. Respir Care. 2007 ; 52: 1687-1694. PMid:18028558

[20] Soo Hoo GW, Wen YE, Nguyen TV. Impact of clinical guidelines in the management of severe hospital acquired pneumonia. Chest. 2005; 128: 2778-2787. PMid:16236955 http://dx.doi.org/10.1378/chest.128.4.2778

[21] Zack JE, Garrison T, Trovillon E. Effect of an education program aimed at reducing the occurrence of ventilator associated pneumonia. Crit Care Med. 2002; 30: 2407-2412. PMid:12441746 http://dx.doi.org/10.1097/00003246-200211000-00001

[22] Ricart M, Lorente C, Diaz E. Nursing adherence with evidence-based guidelines for preventing ventilator associated pneumonia. Crit. Care Med. 2003; 31: 2693-2696. PMid:14605543 http://dx.doi.org/10.1097/01.CCM.0000094226.05094.AA

[23] Chang BL Lee JL, Pearson ML, Kahn KL, Elliott MN, Rubenstein LL. Evaluating quality of nursing care. The gap between theory and practice. J Nurs Adm. 2002; 32: 405-418. PMid:12177562 http://dx.doi.org/10.1097/00005110-200207000-00009

[24] D Ward - British journal of nursing-london-mark, 2000 - internurse.com In: Cormack DFS, ed. The Research Process in Nursing. 3rd edn. Blackwell Science, Oxford:

[25] White, G. C. Equipment theory for respiratory care.Delmar Publishers. 1999.

[26] Lacherade, J. C., De Jonghe, B., Guezennec, P., Debbat, K., Hayon, J., Monsel, A., et al. Intermittent Subglottic Secretion Drainage and Ventilator-associated Pneumonia A Multicenter Trial. Am J Respir Crit Care. 2010; Med 182: $910-917$. 